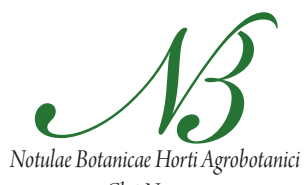

Cluj-Napoca

\title{
Variation in Flower Bud Differentiation and Progression of Floral Organs with Respect to Crop Load in Olive
}

\author{
Cevriye MERT*, Erdoğan BARUT, Ahmet İPEK \\ Uludag University Faculty of Agriculture, Department of Horticulture, Görükle Campus \\ 16059, Bursa, Turkey; cevmert@uludag.edu.tr ("corresponding author)
}

\begin{abstract}
The differentiation of olive floral buds during winter is strictly correlated with flowering in the spring and ultimately with fruit production in autumn and the determination of the time of flower bud induction is important for determining the possible causes of alternate bearing and for improving management practices to correct alternate bearing. The aim of this research was to study the time of flower bud differentiation and developmental steps in the 'Gemlik' olive cultivar in 2008 (off year) and 2009 (on year). The sequence of initiation of the floral organs in each flower bud was sepals, stamens, petals, and gynoecium. There was no visible difference between the time of differentiation and the developmental stage of the floral organs with respect to the 'on' and 'off' years during the study.
\end{abstract}

Keywords: crop load, flower differentiation, olive

\section{Introduction}

Olive (Olea europaea L.) is a very important evergreen fruit tree because olive oil and table olives are an integral part of the human diet. In this tree, the meristems that are able to transform into reproductive meristems are mainly the buds of the axils of leaves of new shoot growth. Biochemical differences between reproductive and vegetative olive buds have been found during autumn and even during summer (Andreini et al., 2008; Malik and Bradford, 2006; Pinney and Polito, 1990).

Flower differentiation in olive trees has long been studied with the aim of regulating annual production because harvesting only occurs in alternate years. Almost no vegetative growth occurs following an extreme year with profuse flowering and heavy fruiting ('on' year), leading to a shortage of flowering sites on the branches, which hold the potential for next year's crop ('off' year) (Goldschmidt, 2005). Flower bud formation requires a series of changes in the differentiation pattern of apical or axillary buds. Flower bud development is a highly complex process that is characterised by two distinct physiological phases: (a) bud initiation and (b) floral bud development (Bernier, 1988). Internal and external signals have a fine regulatory function with regard to the timing of flowering (Fernandez-Escobar et al., 1992) in olive, and it was reported that flower induction occurs in February and March, approximately two months before flowering (Fabbri and Alerci, 1999; Hartmann, 1951; Monselise and Goldschmidt, 1982).

Developing fruits have been shown to have a significant effect on the development of flower buds for the following season, and it was suggested that the developing fruit is a strong sink that competes with vegetative growth for metabolites in various fruit species (Monselise and Goldschmidth, 1982). In olive, however, this relationship is not clear and appears not to be particularly significant. Some workers have found correlations between 'on' and 'off' years with primary metabolites, such as carbohydrates (Seyyednejat et al., 2001) and polyamines (Pritsa and Voyiatzis, 2004), and an increase in the starch content during winter in the central axis of lateral potentially reproductive buds has been reported (De la Rosa et al., 2000). In contrast, others researchers did not find a competitive effect between the developing fruiting and vegetative growth with regard to basic organic metabolites (Fernandez-Escobar et al., 1999, 2004). Stutte and Martin (1986) found a uniform level carbohydrates in the leaves of bearing and non bearing trees, and Andreini et al. (2008) reported no differences between the axillary buds sampled from the shoots of 'on' and 'off' years in olive cultivars. Furthermore, there is no sufficient information about the effects of crop load (alternate bearing) on olive flower bud differentiation and development, with only a few studies on the differentiation time of flower buds with respect to the crop load. However, determining the time of flower bud induction is important for defining the possible causes of alternate bearing and for developing management practices to correct alternate bearing.

Thus, the objective of this study was to determine the time of flower bud differentiation and the developmental stages of the flower bud of the 'Gemlik' olive cultivar from both morphological and histological perspectives. The effect of different crop load on the time of flower bud differentiation and the correlation between 2008 ('off' year) 
80

and 2009 ('on' year) was also determined with respect to the time of differentiation.

\section{Material and methods}

\section{Plant material}

The experiment was conducted in the olive orchard in Gorukle, Bursa, Turkey (latitude, 29 04' E; longitude, $40^{\circ} 39^{\prime} \mathrm{N}$ ) using the 'Gemlik' olive cultivar. This cultivar is one of the most important black table olive cultivars in Turkey and has been grown in counties that are located near the Marmara Sea. This cultivar shows various degrees of alternate bearing from year to year.

The bud samples were collected from the trees of this cultivar both in the 'off' and 'on' years from January to the middle of May in 2008 and 2009. This period was selected based on visible anatomical changes in longitudinal sections of the floral buds. Four 25-year-old trees were used in the study, and samples were collected according to a randomised block design. Axillary buds were collected at $10-$ day intervals. The buds were fixed in FAA solution $(10 \%$ formalin, 5\% glacial acetic acid, 50\% ethanol and 35\% water, by volume) (Sass, 1958) and then examined using light and scanning electron microscopy after treated with standard procedures.

\section{Morphologicalobservations}

\section{Light microscopy (LM)}

Bud samples prefixed in FAA solution were transferred to $70 \%$ ethanol $(\mathrm{EtOH})$ for two days. The samples were then dehydrated in 50\%, 70\%, and 95\% EtOH series and twice in $100 \% \mathrm{EtOH}$. The samples were gradually infiltrated and embedded in paraffin using standard procedures (Brooks et al., 1950). The embedded ovaries were sectioned to 7 - to $8-\mu \mathrm{m}$ thickness using a rotary microtome, stained with an iron-alum and haematoxylin combination (Brooks et al., 1950) and examined under a light microscope (BH-2, Olympus Optical Co., Tokyo, Japan) equipped with an Olympus DP20 camera.

\section{Scanning electron microscopy (SEM)}

The FAA-prefixed bud samples were dissected using an Olympus SZ 6045 TR stereomicroscope before processing for SEM. The buds were rinsed twice (10 min each) in $50 \% \mathrm{EtOH}$ to remove the FAA from the plant tissue and were stored in $50 \% \mathrm{EtOH}$ during dissection to prevent desiccation. The samples were dehydrated in $\mathrm{EtOH}$ series (one time in 50\%, 70\% and 95\% $\mathrm{EtOH}$ and then twice in $100 \%$ for $10 \mathrm{~min}$ ). The samples were dried to the critical point and mounted on stainless-steel stubs with carbon tape before being gold coated using a sputter coater (Polaron SC 7620, VG Microtech, Uckfield, UK). The samples were examined using a scanning electron microscope (JSM-5600LV, Jeol, Tokyo, Japan).

\section{Stereomicroscopy}

The lengths of the flower buds were measured from January to April to determine the growth and morphological changes in the buds. The flower bud samples were observed and measured under a stereomicroscope equipped with an Olympus DP20 camera.

\section{Results and discussion}

The time of flower bud differentiation and the developmental stages of the floral buds (sepal, petal, stamen and pistil formation) of cultivar 'Gemlik' in 2008 ('off' year) and 2009 ('on' year) are presented in Tab 1. As shown, the differentiation of the flower buds began in the middle of Tab. 1. Sequence of events during the differentiation and inner development of flower bud of 'Gemlik' cultivar 2008 (off year) and 2009 (on year)

\begin{tabular}{|c|c|c|c|}
\hline $\begin{array}{l}2008 \text { year } \\
\text { (off year) }\end{array}$ & Bud development stage & $\begin{array}{c}2009 \text { year } \\
\text { (on year) }\end{array}$ & Bud development stage \\
\hline 01 January & $\begin{array}{l}\text { Light dome shape of apical meristem } \\
\text { (Ap.m) and view of L1,L2,L3 layers }\end{array}$ & 1 January & $\begin{array}{l}\text { Light dome shape apical meristem } \\
\text { (Ap.m) and view of L1,L2,L3 layers }\end{array}$ \\
\hline 10 January & Light dome Ap.m and view of L1,L2,L3 layers & 12 January & Light dome Ap.m and view of L1,L2,L3 layers \\
\hline 21 January & Light dome Ap.m and view of L1,L2,L3 layers & 22 January & Light dome Ap.m and view of L1,L2,L3 layers \\
\hline 02 February & Light dome Ap.m and view of L1,L2,L3 layers & 03 February & Light dome Ap.m and view of L1,L2,L3 layers \\
\hline 14 February & Light dome Ap.m and view of L1,L2,L3 layers & 10 February & Light dome Ap.m and view of L1,L2,L3 layers \\
\hline 25 February & Light dome Ap.m and view of L1,L2,L3 layers & 23 February & Light dome Ap.m and view of L1,L2,L3 layers \\
\hline 03 March & Ap.m are in mitotic activity & 03 March & Ap.m are in mitotic activity \\
\hline 17 March & The first evidence of flower formation & $18 \mathrm{March}$ & The first evidence of flower formation \\
\hline 22 March & Ap.m are in triad stage & 23 March & Ap.m are in triad stage \\
\hline 31 March & Appearance of three protuberances & 01 April & Appearance of three protuberances \\
\hline 10 April & Sepal (Sp), Petal $(\mathrm{Pt})$ and Stamen $(\mathrm{St})$ are forming & 10 April & Sepal (Sp) is forming \\
\hline 21 April & $\mathrm{Sp}, \mathrm{Pt}$, St and Carpel (Cr) are forming & 20 April & Sp, Petal $(\mathrm{Pt})$ and Stamen $(\mathrm{St})$ are forming \\
\hline 28 April & $\mathrm{Sp}, \mathrm{Pt}, \mathrm{St}$ and $\mathrm{Cr}$ are in developmental stage & 04 May & Sp, Pt, St and Carpel (Cr) are in developmental stage \\
\hline 01 May & Appearance of microspore mother cells in anther & 10 May & Appearance of microspore mother cells in anther \\
\hline 12 May & Unopened perfect flower & 18 May & Unopened perfect flower \\
\hline 18 May & Anthesis stage & 25 May & Anthesis stage \\
\hline
\end{tabular}



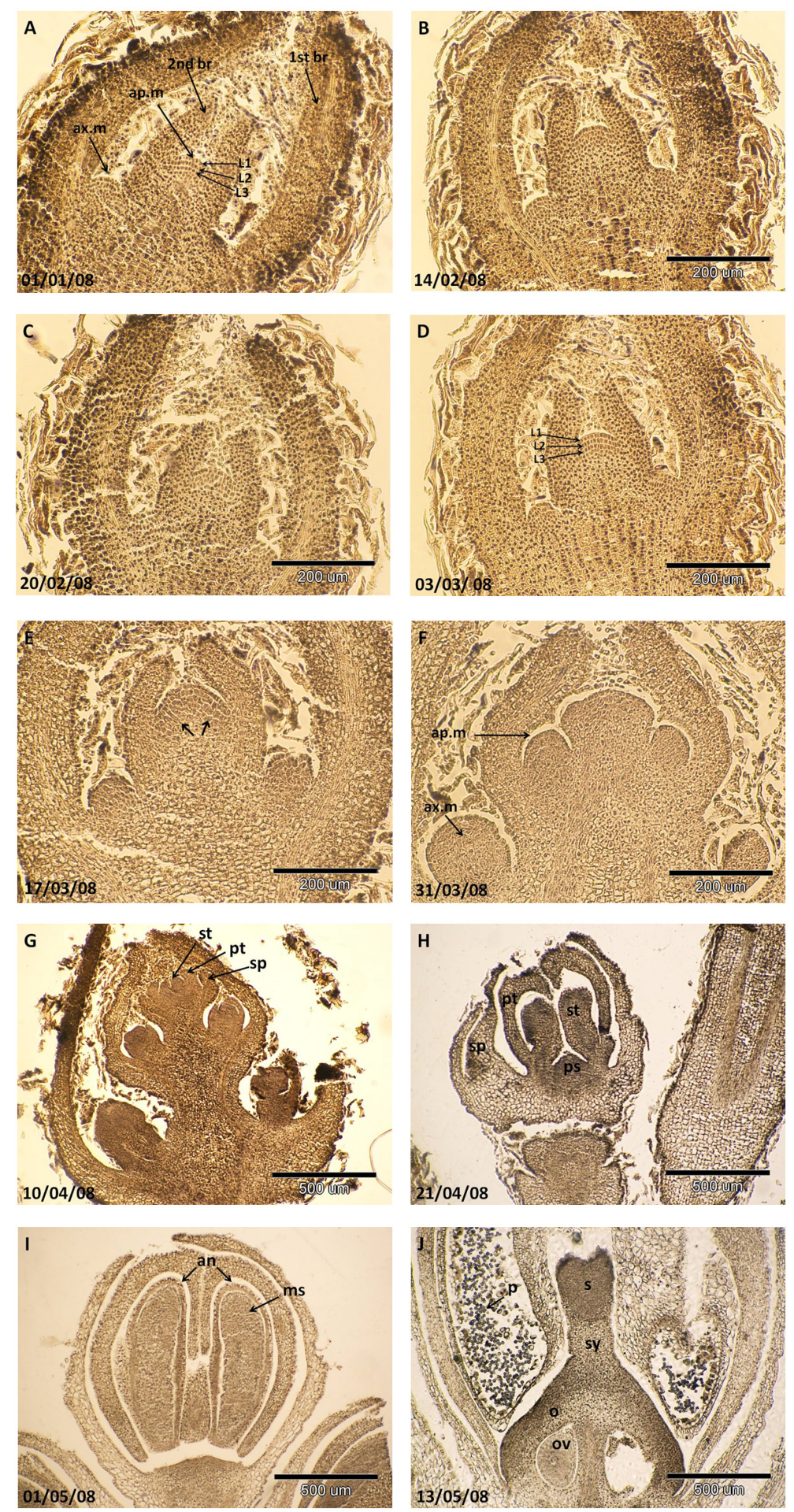

Fig. 1. Anatomical changes during differentiation in olive floral buds of 'Gemlik' from 1 January to 13 May in 2008 (off year). Appearance of vegetative buds before development of flower parts has started. Two visible pairs of bracts well developed, flattenedshape apical meristem, beginning of meristematic activity in the axils of the basal bracts (1/1)(3/3). (A, B, C, D). Bud section showing the first evidence of flower formation (17/3). Intense mitotic activity (arrows) and zonation of cells in the dome shape apical and axillary meristems (E). Appearance of three protuberances (31/3) (F). Floral whorls primordial development. Sepals, petals and stamens are forming. Lateral flowers are becoming evident (10/4) (G). Sepals, petals, stamens are now evident. Pistil is forming $(21 / 4)(\mathrm{H})$. Appearance of microspore mother cells in anther (01/5) (I). At anthesis, of a pistil of a hermaphrodite flower with a completely differentiated embryo sac $(13 / 5)(\mathrm{J}) . \mathrm{an}=$ anther; ap. $\mathrm{m}=$ apical meristem; ax.m= axillary meristem; $\mathrm{br}=$ brakte leaf; $\mathrm{ms}=$ microspore mother cell; $\mathrm{o}=$ ovary; ov= ovule; $\mathrm{s}=$ stigma; $\mathrm{st}=$ stamen; $\mathrm{sp}=$ sepal; sy= style; $\mathrm{p}=$ pollen; $\mathrm{pt}=$ petal 
82

March both in the 'on' and 'off' years. However, the stamen and carpel formation and the full bloom date were 7-9 days later in 2009 ('on' year) than the previous year.

Fig. 1 and 2 show the axial-longitudinal sections of buds in the process of flower differentiation and development, as observed using a light microscope. In January, the olive floral buds consisted of the apical meristem and one pair of developed axillary meristems, regions of the organs in which developmental changes were noted. Both meristems were covered with bracts (Fig. 1A, 2A). In this period, the shoot apical meristem consists of three cell layers, designated L1, L2 and L3, as shown by Fabbri and Alerci
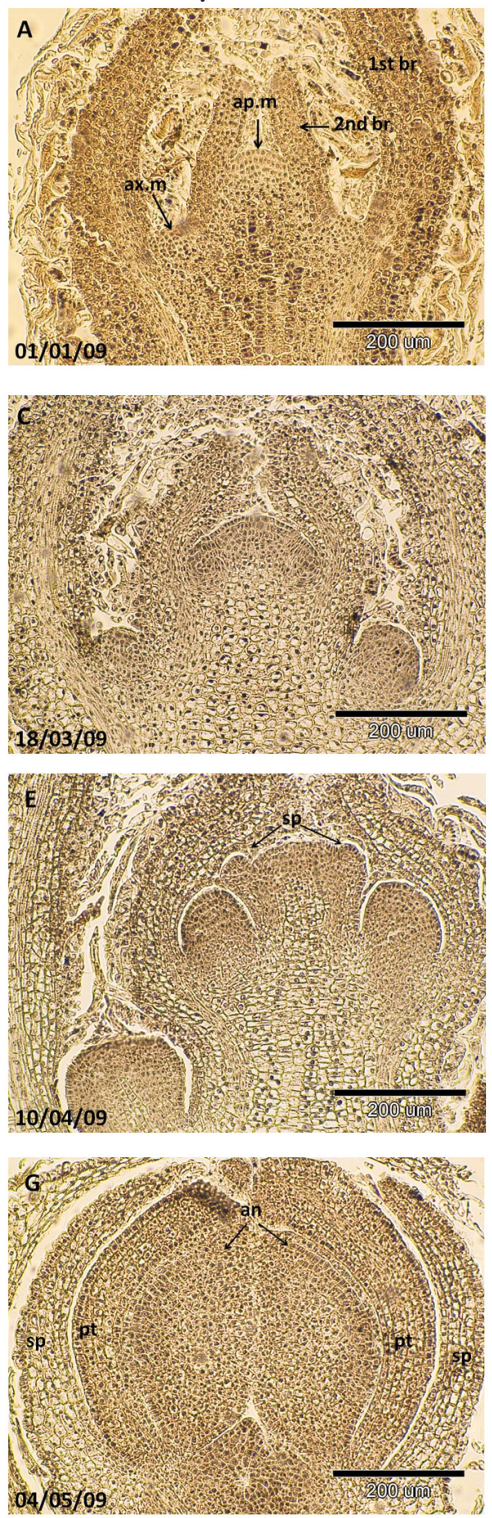

(1999), which give rise to separate cell lineages (Fig. 1A and D). These cell layers are distinguished by their positions and patterns of cell division. The cells of the L1 layer divide anticlinally throughout development and form the epidermis of the plant; the cells of the L2 layer also divide anticlinally within the meristem but in other planes during differentiation. Conversely, the cells of the deepest layer, L3, divide in all planes. Both the L2 and L3 layers contribute to the body of the plant in proportions that vary in different organ types. The L2 layer is generally the source of the germ cells (Stewart, 1978).
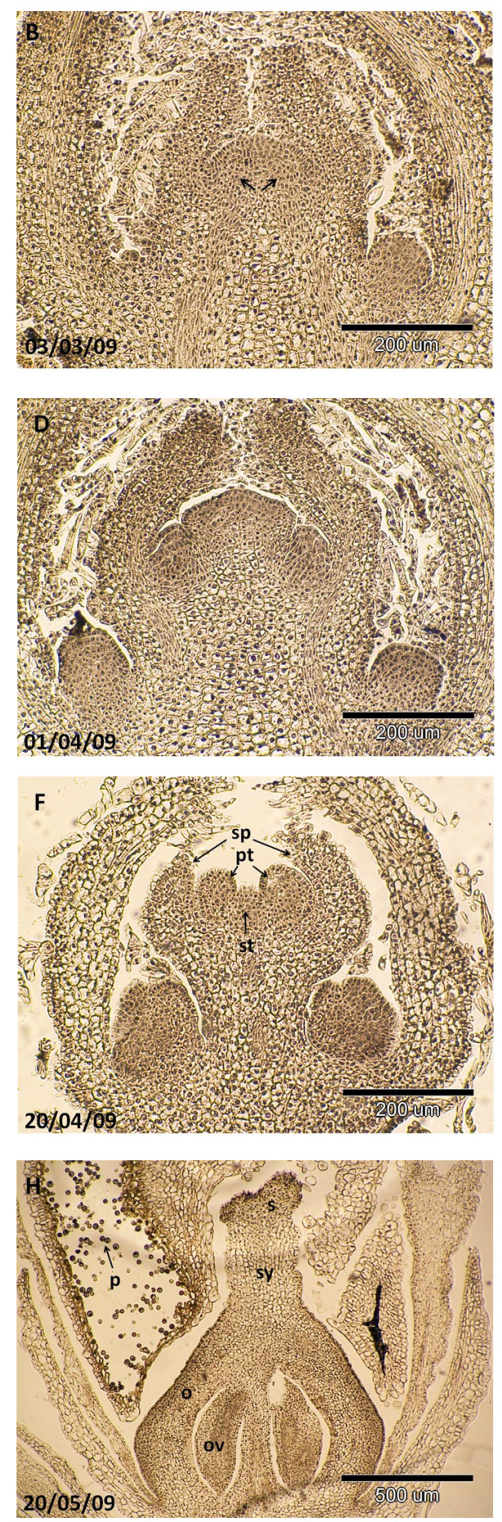

Fig. 2. Anatomical changes in differentiation of olive floral buds of 'Gemlik' from 1 January to 20 April in 2009 (on year). Appearance of vegetative buds before development of flower parts has started (A, B, C, D). Intense mitotic activity (arrows) and zonation of cells in the dome shape apical (03/3) (B). Bud showing the first evidence of flower formation (18/3) (C). Appearance of three protuberances (01/4) (D). Floral whorls primordial development. Sepals are forming. (10/4) (E). Sepals, petals, stamens are now evident (20/4) (F). Appearance of microspore mother cells in anther (04/5) (G). At anthesis of a pistil of a hermaphrodite flower with a completely differentiated embryo $\operatorname{sac}(20 / 5)(\mathrm{H})$. an = anther; ap.m= apical meristem; ax.m= axillary meristem; br= brakte leaf; $\mathrm{ms}=$ microspore mother cell; $\mathrm{o}=$ ovary; $\mathrm{ov}=$ ovule; $\mathrm{s}=$ stigma; $\mathrm{st}=$ stamen; $\mathrm{sp}=\mathrm{sepal} ; \mathrm{sy}=\mathrm{style} ; \mathrm{p}=$ pollen; $\mathrm{pt}=$ petal 
In February, an enlargement of the apical meristem can be observed (Fig. 1B and C). At the beginning of March, anticlinal mitotic divisions resulted in the zonation of the apical meristem, which could have a dome shape or a widened dome shape. In the case of the initiation of peripheral mitotic activity (bract primordia), the dome-shaped apical meristem became a widened dome. Cell divisions in both tips of the apical meristem can clearly be observed in Fig. $1 \mathrm{E}$ and, particularly, in Fig. 2B, and the apical meristem was nonsegmental. In both years, it was determined that differentiation in the buds occurred during March 17-18. In addition, development in the axillary meristems began, and the meristems enlarged (Fig. 1E, 2C). Several investigators have studied the time of flower differentiation in olive, and it was reported that flower induction occurred in February and March (De Almeida, 1940; Fabbri and Alerci, 1999; Hartmann, 1951; Kitsaki et al., 2010; Morettini, 1937), in accordance with this study findings.

The flower buds collected from the end of March to the beginning of April exhibited the first phases of floral differentiation: in all the apices, three protuberances were actively growing, with the central one being the largest
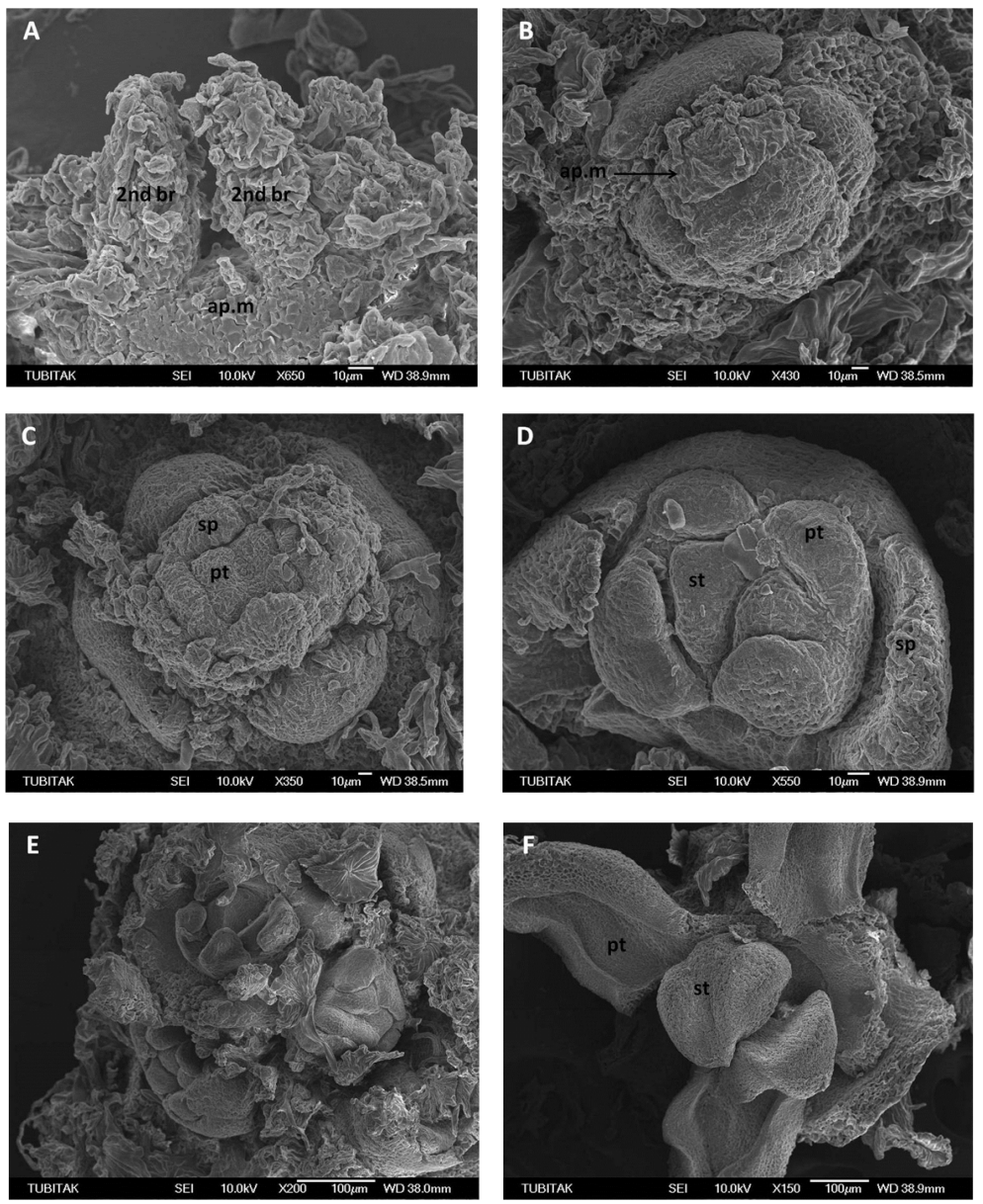

Fig. 3. Scanning electron micrographs showing the apical meristem 'Gemlik' as it changes from the vegetative to the reproductive stage. View of vegetative bud (A), Appearance of three protuberances (triad stage) (B), sepal and petal formation (C), petal and stamen formation $(\mathrm{D})$, view of flowers $(\mathrm{E})$, petals and stamens are now evident $(\mathrm{F})$. ap.m=apical meristem; bt= brakte leaf; st= stamen; $\mathrm{sp}=$ sepal; $\mathrm{pt}=$ petal 


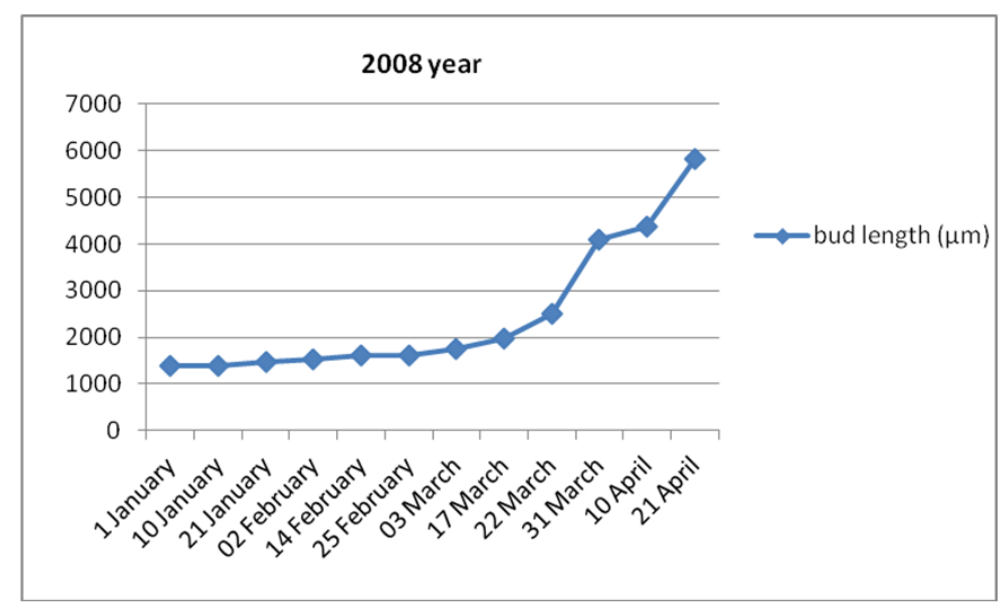

Fig. 4 . The seasonal changes in bud growth following the differentiation and development of flower buds in 2008 (off year)

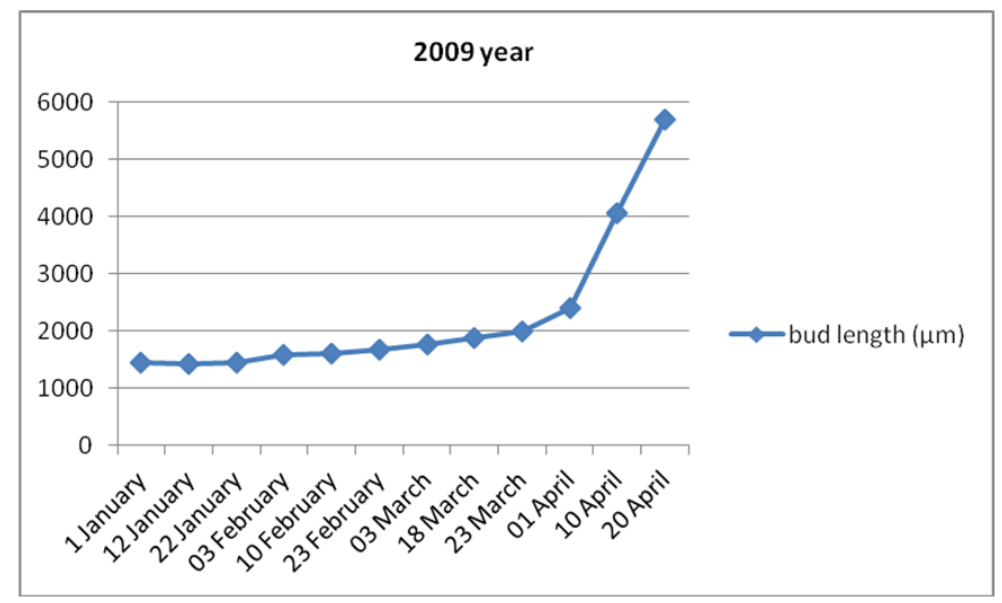

Fig. 5. The seasonal changes in bud growth following the differentiation and development of flower buds in 2009 (on year)

According to our anatomical observations of flower buds, it may be stated that there was no difference in the timing of flower differentiation and the timing of the developmental stages of 'Gemlik' flower buds between 2008 ('off' year) and 2009 ('on' year). Consequently, the crop load could not represent a limiting factor for apex development, a result in agreement with the results obtained by Andreini et al. (2008), Fabbri and Alerci (1999) and Pinney and Polito (1990).

Fig. 4 and 5 present the seasonal changes in bud growth following the differentiation and development of flower buds in 2008 and 2009. The longitudinal diameter of buds rapidly increased until late April but showed little increase thereafter. According to the measurements of the axillary buds, the mean bud length was approximately $1400-1500$ $\mu \mathrm{m}$ in January and $1600 \mu \mathrm{m}$ in February in both years. In the middle of March, the mean bud length increased markedly and reached $1900 \mu \mathrm{m}$. At the beginning of April, the mean bud length was $4095.02 \mu \mathrm{m}$ in 2008 and 2393.19 $\mu \mathrm{m}$ in 2009; in fact, based on our examination of the sections, the timing of the developmental stages of the buds was slower in 2009 than 2008 with respect to this period.
It was determined that, at the end of April, the mean bud length was $5823.53 \mu \mathrm{m}$ in 2008 and $5690.62 \mu \mathrm{m}$ in 2009.

\section{Conclusions}

In conclusion, there were no significant differences in the timing of differentiation and the ensuing developmental stages of flower buds between the 'on' and 'off' years in this cultivar. Consequently, it was determined that the timing of the differentiation process and ensuing developmental stages of the flower buds did not depend on the crop load of the tree. The differentiation process occurred in the middle of March in both years. The morphological differentiation started with the enlargement of the central growth cone and continued with the new formations. In this way, three flowers were formed from the embryonic tissues of the central growth cone. Soon after the differentiation process was complete, the primordia of the sepal, petal, stamen, and ovule developed rapidly.

Based on the results of this study, we suggest that, with regard to the reason(s) for alternate bearing in this cultivar, it may be useful to direct attention to the biochemical 
and hormonal relationships in the buds and in the entire tree.

\section{Acknowledgements}

The authors wish to thank The Commission of Scientific Research Projects of Uludag University for their financial support for this study through project, 2007/9.

\section{References}

Andreini L, Bartolini S, Guivarc'h A, Chriqui D, Vitagliano C (2008). Histological and immunohistochemical studies on flower induction in the olive tree (Olea europaea L.). Plant Biol 10:588-595.

Brooks RM, Bradley MV, Anderson TI (1950). Plant Microtechnique (manual). Univ. Of California, Davis, $70 \mathrm{p}$.

De Almeide FJ (1940). Safra e contra-safra na oliveira. Bul Port Minist da Agri No. 7. Lisboa.

De la Rosa R, Rallo L, Rappoport H (2000). Olive floral bud growth and starch content during winter rest and spring budbreak. HortScience 35:1223-1227.

Fabbri A, Alerci L (1999). Reproductive and vegetative bud differentiation in Olea europea L. J Hort Sci Biotechnol 74(4):522-527.

Fernandez-Escobar R, Benlloch M, Navarro C, Martin GC (1992). The time of floral induction in the olive. J Amer Soc Hort Sci 117:304-307.

Fernandez-Escobar R, Moreno R, Garcia-Creus M (1999). Seasonal changes of mineral nutrients in olive leaves during the alternate-bearing cycle. Scientia Hortic 82:25-45.

Fernandez-Escobar R, Moreno R, Sanchez-Zamora MA (2004). Nitrogen dynamics in the olive bearing shoot. HortScience 39:1406-1411.

Goldschmidt EE (2005). Regolazione dell'alternanza di produzione negli alberi da frutto. Italus Hortus 12(1):11-17.
Hartmann HT (1951). Time of floral differentiation of the olive in California. Botanical Gazette 112:323-327.

Kitsaki CK, Andreadis E, Bouranis DL (2010). Developmental events in differentiating floral buds of four olive (Olea europaea L.) cultivars during late winter to early spring. Flora 205:599-607.

Malik SA, Bradford JM (2006). Changes in oleuropein levels during differentiation and development of floral buds in “Arbequina” olives. Sci Hortic 110:274-278.

Monselise SP, Goldschmidt EE (1982). Alternate bearing in fruit trees. Horticultural Reviews 4:128-173.

Morettini A (1937). Importance de l'poque de diffrenciation des bourgeons bois en bourgeons fleurs chez l'olivier. Bull Mens Fd Int O1icult 11:247-254.

Pinney K, Polito VS (1990). Flower initiation in 'Manzanillo' olive. Acta Hort 286:203-205.

Pritsa TS, Voyiatzis DG (2004). Seasonal changes in poly amine content of vegetative and reproductive olive organs in relation to floral initiation, anthesis, and fruit development. Aust J Agric Res 55:1039-1046.

Sass JE (1958). Botanical Microtechnique. Iowa State Univ. Press Ames, Iowa, $228 \mathrm{p}$.

Seyyednejad M, Ebrahimzadeh H, Talaie A (2001). Carbohydrate content in olive 'Zard' cv. and alternete bearing pattern. International Sugar J 103:84-87.

Stewart RN (1978). Ontogeny of the primary body on chimeral forms of higher plants, 133-160 p. In: Subtleny S, Sussex IM (Eds.). The clonal basis of development. New York Academy Press.

Stutte GW, Martin GC (1986). Effect of killing the seed on return bloom of olive. Scientia Hort 29:107-113. 